\title{
NOS MOINHOS DO CÁRCERE: DALCÍDIO JURANDIR, LEITOR DE DOM QUIXOTE DE
}

LA MANCHA.

Viviane Dantas Moraes ${ }^{1}$

Eu vivo pelo milagre da minha imaginação

(trecho de carta de Dalcídio Jurandir, presídio São José, 1936)

RESUMO: A relação entre a experiência do confinamento e literatura é normalmente vinculada ao aspecto da criação de obras que narram tal acontecimento, como o consagrado romance Memórias do Cárcere, de Graciliano Ramos. No entanto, a proposta desse trabalho aborda uma reflexão sobre os papéis exercidos pelos autores em uma situação de exceção, a partir da ótica do escritor na sua experiência enquanto um leitor no cárcere. Um dos objetivos é investigar, em que medida, o contato com obras literárias em um contexto de opressão pode ter impulsionado os projetos estéticos e éticos do escritor-leitor. Trata-se, portanto, da experiência de prisão vivida por Dalcídio Jurandir, durante o Estado Novo, no Pará, na década de 1930. O escritor foi militante do Partido Comunista e esteve, por duas vezes, preso e incomunicável, no presídio São José, em Belém. Durante a prisão, Dalcídio Jurandir lê o romance Dom Quixote de la Mancha, de Miguel de Cervantes. Palavras- chave: Cárcere. Leitor. Dalcídio Jurandir. Dom Quixote

Abstract: The relationship between the experience of confinement and literature is usually linked to the aspect of creating works that narrate such an event, such as Graciliano Ramos' renowned novel Memórias do Cárcere. However, the proposal of this work approaches a reflection on the roles exercised by the authors in a situation of exception, from the perspective of the writer in his experience as a reader in the jail. One of the objectives is to investigate, to what extent, contact with literary works in a context of oppression may have propelled the aesthetic and ethical projects of the writer-reader. It is, therefore, the experience of imprisonment experienced by Dalcídio Jurandir during Estado Novo, Pará, in the 1930s. The writer was a Communist Party militant and was twice arrested and incommunicado in São José prison, in Belém. During his imprisonment, Dalcídio Jurandir reads the novel Don Quixote de la Mancha by Miguel de Cervantes.

Keywords: Prison. Lector. Dalcídio Jurandir. Dom Quixote

Em 9 de maio de 1936, o escritor paraense Dalcídio Jurandir (1909-1979), à época encarcerado no presídio São José, em Belém, no Pará, devido à sua militância comunista e luta contra o fascismo durante a Era Vargas, finaliza a leitura de uma das mais importantes obras da literatura universal. Trata-se de "Dom Quixote de La Mancha", de Miguel de Cervantes, cuja imagem da capa apresentamos a seguir.

\footnotetext{
${ }^{1}$ Professora adjunta de Língua e Literatura francesa do Departamento de Letras da Universidade Federal do Maranhão. Email: viviane.danttas@gmail.com.
} 


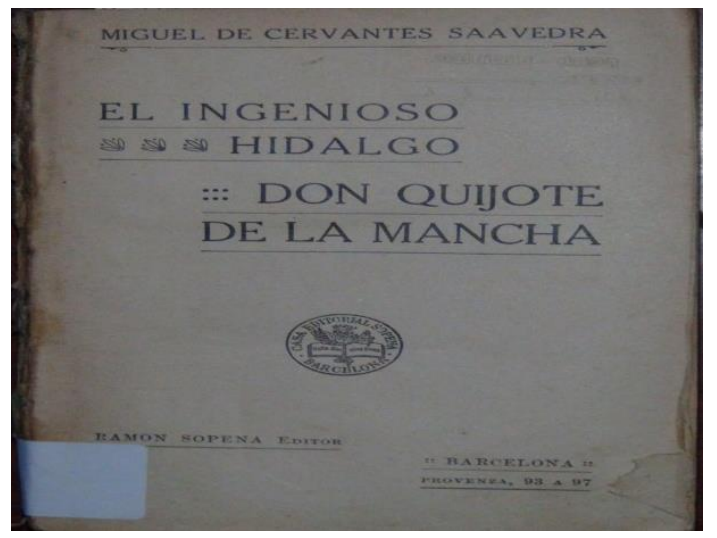

Imagem 1: Capa da edição de Dom Quixote de la Mancha lida por Dalcídio Jurandir no cárcere. (Acervo Casa Rui Barbosa)

A informação tão precisa nos é fornecida pelo próprio escritor-leitor, em anotação feita a lápis, na última página do romance, que faz parte do acervo de sua biblioteca pessoal, doada para a Fundação Casa Rui Barbosa, no Rio de Janeiro. A anotação está assim registrada:

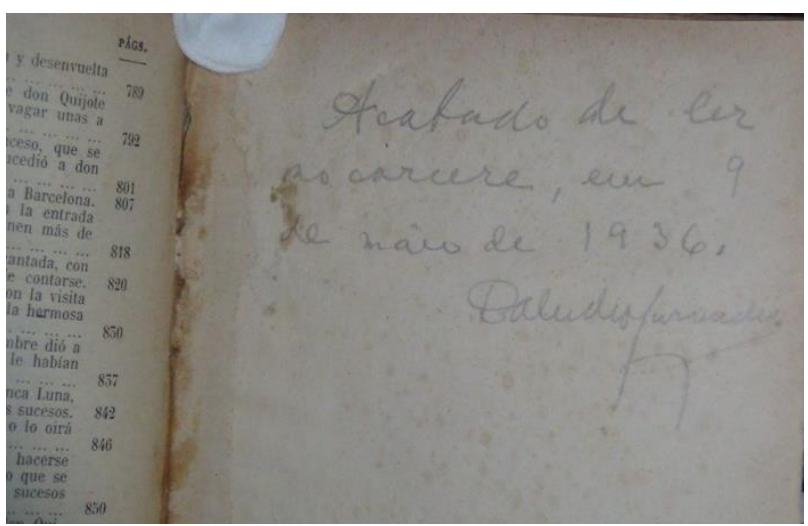

Imagem 2: Anotação do escritor no final da edição: Acabado de ler no cárcere, em 9 de maio de 1936, Dalcídio Jurandir (Acervo Casa Rui Barbosa)

Ou seja, há mais de oitenta anos, o escritor deixou um recado, um registro que demonstra a necessidade de se atentar para seu ato de resistência, a uma subversão às condições opressoras impostas a ele naquele momento de isolacionismo, de confinamento, de injustiça e de proibições.

Ao enfatizar o lugar de onde havia cumprido tal missão, ou seja, "no cárcere”, Dalcídio Jurandir nos lança uma mensagem que precisamos melhor compreender. Qual o sentido da prisão para ele? Qual o sentido da luta do homem contra as injustiças? O que pensar numa condição de exceção, especialmente no seu caso, onde mesmo o acesso à leitura pode ser censurado, perigoso? O que é lido 
nesse contexto adquire de fato outra perspectiva? Transmuta-se em pensamento e em criação? Em princípio, portanto, a breve, mas significativa anotação do escritor revela que ler "no cárcere" e/ou fora dele, nos denota, sim, uma importante diferença.

Dalcídio Jurandir nasceu em Ponta de Pedras, na Ilha do Marajó, no Pará. Escreveu e publicou 11 (onze) livros, sendo que 10 (dez) deles formam o chamado Ciclo do Extremo Norte: "Chove nos Campos de Cachoeira" (1941), "Marajó" (1947), "Três Casas e um Rio" (1958), "Belém do GrãoPará” (1960), "Passagem dos Inocentes” (1963), "Primeira Manhã” (1968), "Ponte do Galo” (1971), “Os Habitantes” (1976), “Chão de Lobos” (1976), "Ribanceira” (1978) e um livro publicado isoladamente desse ciclo, intitulado "Linha do Parque" (1959). O Ciclo do Extremo Norte, produzido em meio às turbulências, dificuldades financeiras e entraves do mercado editorial, conseguiu o prêmio Machado de Assis, concedido pela Academia Brasileira de Letras, em 1972.

O escritor marajoara exerceu fortemente suas atividades de militância no Partido Comunista e atuou na luta contra o fascismo, sobretudo na década de 1930. Essa é uma faceta do autor ainda pouco explorada, a da resistência como militante. Tal exercício lhe rendeu, no entanto, no âmbito das ações repressoras do governador Magalhães Barata, na Era Vargas, em terras paraenses, seu encarceramento por duas vezes: em 1936 e 1937. Segundo o crítico Renard Perez (1964), um ano antes da primeira prisão, Dalcídio Jurandir já sinalizava suas ideias esquerdistas em público:

\footnotetext{
Vai falar no largo da Pólvora. Sobe nos caixões de comício de subúrbio. Em 1936 é preso, preso incomunicável, nunca ouvido, sem que nem mesmo jornal lhe permitiam folhear. Sua sorte é o tenente Soares - delegado de Gurupá em 1931 e aquela altura Comissário de polícia - que aparece de vez em quando no plantão da Central e lhe leva, dentro do paletó, um jornalzinho do dia. A prisão - acredita o escritor - trará ao menos uma vantagem: oferecerá a sempre adiada ocasião de ler Dom Quixote por inteiro num só fôlego. [...] Em 1937 é preso novamente, por três meses, por campanha contra o fascismo. Fica na cadeia São José, num xadrez comum, onde nem verba sequer havia para a alimentação dos detidos (PEREZ, 1964, p. 268).
}

Renard Perez foi um dos poucos críticos, senão o único, a falar mais abertamente, embora de forma não detalhada, sobre essa, digamos, cronologia do cárcere de Dalcídio Jurandir. No entanto, quanto à informação sobre a leitura do Dom Quixote, Perez comete um equívoco - na obra citada acima - ao dizer que o escritor não havia terminado a leitura por terem confiscado a obra. Ressalta-se, entretanto, que a edição lida e rabiscada por Dalcídio foi por sorte encontrada, e como pode ser observado nas imagens acima há prova da finalização de sua leitura deixada pelo próprio autor. 
Interessante salientar que ao içarmos as motivações do encarceramento aos termos potenciais com que o escritor-leitor comprova seu acesso ao texto cervantino, vemos que Jurandir registra a finalização da leitura como um pequeno testemunho de uma conquista e, sobretudo, como um ato de resistência.

É justamente sobre essa atitude de Dalcídio Jurandir em condição carcerária, enquanto ato de resistência, que pretendemos refletir a título de um ensaio não apenas em relação ao ato em si, mas a forma como este reverbera na sua criação artística e intelectual, e aqui cabe citar Alfredo Bosi quando diz que a resistência pode estar na escrita de forma imanente. Deste modo, tratamos da relação entre literatura e resistência inspirada pelo pensamento do crítico literário a partir de seu ensaio "Narrativa e resistência", que abriu caminho para muitas interpretações ao especular que "resistência é um conceito originalmente ético e não estético" (BOSI, 2002, p.11). Ainda nesse sentido, uma observação importante, visto que falamos de situações envolvendo a exceção por motivações políticas, é a de Elcio Cornelsen:

Em geral, há uma gama de sentidos atribuídos ao conceito de "resistência", seja como resistência política, social, cultural e literária. Em sua maioria, esses sentidos são empregados para se refletir sobre posturas e práticas de resistência a regimes de exceção (CORNELSEN, 2014, p. 96).

Interessante notar que todos os elementos e possibilidades de se pensar a resistência citados por Cornelsen, fazem parte da construção do discurso literário de Dalcídio Jurandir e perpassam seu projeto estético, que não deixa de ser movido por uma ética: aquela comprometida em dar visibilidade aos assombrados pelas mais variadas formas de indigência.

A leitura no cárcere configura-se por si só uma postura e uma prática de resistência a uma condição de exceção. É possível notar na produção do autor a sua preocupação com as questões políticas, sociais, culturais e literárias. Podemos considerar, portanto, que o conjunto da obra de Dalcídio perpassa pela resistência, e mesmo que não contextualize regimes de exceção por excelência, denunciam a violência à vida humana, ao dialogar fortemente com outras facetas e formas de repressão, em particular, por ser possível ler as narrativas dalcidianas como escritas em que se constroem espaços de sobrevivência, possíveis de serem relacionados com o paradigma da sobrevivência interposto no Estado de Exceção, dessa forma expressando aquelas condições próprias a que o filósofo Giorgio Agamben, inspirado pelos estudos de Walter Benjamin, chamou vida nua. 
É certo que os personagens dos romances de Dalcídio Jurandir não aparecem em um campo de concentração nazista, nem atuam no palco cinzento de Samuel Beckett, por exemplo, mas habitam num lugar de opressão e trazem consigo as marcas da Exceção ${ }^{2}$, representados na produção dalcidiana pela experiência da fome, da infâmia, da decadência dos valores humanos; o abandono à sombra da lei e dos deveres do estado: os infortúnios causados pelo adoecimento sem os cuidados clínicos mínimos, pelo analfabetismo, pelo despojamento e expropriação em suas formas mais perversas, pela humilhação fruto de atitudes discriminatórias e condenatórias. Enfim, condições que no corpus dalcidiano formam um conjunto considerável de párias, desafortunados e desamparados.

Ao que consta, não há, além das cartas trocadas com a esposa durante a prisão, uma produção literária de Dalcídio Jurandir voltada exclusivamente à sua experiência no cárcere. Nessas correspondências há registros de outras leituras feitas por ele durante o período. Até o momento, descobriram-se evidências de que ele leu, além de Dom Quixote de la Mancha, uma edição comemorativa em espanhol; Fausto, de Goethe, em francês; Origem da Família, do Estado e da propriedade privada, de Friedrich Engels; alguns romances de Fiódor Dostoievski (é mencionado nas cartas apenas o nome do autor); e A novela, de Nikolai Gogol.

A década de 1930 foi uma época importante na carreira literária do autor que tentava reescrever e finalizar seu primeiro romance Chove nos Campos de Cachoeira, assim como o seu segundo romance Marajó, ambos retomados em 1938, após sua saída definitiva da prisão. Portanto, nota-se que tal década em que o escritor passa pela experiência do cárcere é um momento crucial que demarca os primórdios de sua carreira literária. Deste modo, busca-se investigar, além de outras evidências de leituras, de que forma estas influenciaram na construção da produção literária e intelectual na sua relação com a resistência, potencializada pela experiência traumática da repressão, do isolamento e do abandono.

O fato de que Dalcídio Jurandir esteve preso e encarcerado e ter lido várias obras literárias e filosóficas na prisão, com ênfase para Dom Quixote de La Mancha, figura apenas como uma informação biográfica do pouco registrado que é possível acessar sobre sua história na prisão. No entanto, no âmbito dos estudos sobre a resistência e de suas relações com o Estado de Exceção, tal momento da vida do autor transmuta-se numa riquíssima cena que pode contribuir na compreensão sobre a construção literária do Ciclo do Extremo Norte. O ciclo narra a trajetória de um mesmo

\footnotetext{
${ }^{2}$ Conforme o estudo desenvolvido na tese de doutorado intitulada A vida nua em Dalcídio Jurandir: metamorfoses do estado de Exceção (MORAES, 2017).
} 
personagem chamado Alfredo que, em busca de uma vida melhor, sai da Ilha do Marajó para a capital Belém, mas acaba colecionando experiências e testemunhos da tragédia humana, social e política na Amazônia. Embora a cada história narrada sua decepção só aumente, há sempre uma busca por algo. No último romance do Ciclo, Ribanceira, Alfredo, já adulto, volta desolado para o Marajó a fim de herdar as ruínas deixadas pelo pai. Nesse sentido, uma das hipóteses dentro da proposta de reflexão apresentada, condiz com uma possível aproximação entre os personagens Alfredo e Dom Quixote, assim como a análise da influência de Dom Quixote, o romance, na concepção do ciclo literário sobre a Amazônia.

A propósito, embora Dalcídio Jurandir já tenha sido comparado ao escritor francês Marcel Proust (1871-1922), a respeito da semelhança entre os projetos estéticos, pouco se questiona sobre a criação do ciclo dalcidiano, sendo que o escritor paraense, em âmbito nacional, optou por um formato literário audacioso e de difícil constituição, raramente seguido por outros romancistas. Portanto, o projeto estético-literário de Dalcídio Jurandir, supostamente iniciado em 1929, com a primeira versão não publicada de Chove nos Campos de Cachoeira, entra no ostracismo na década de 1930, quando o autor resolve se dedicar à militância comunista e vive a experiência do cárcere, resgatando sua atividade de romancista apenas no final dos anos trinta. Dizemos supostamente porque, até então, Dalcídio havia escrito duas obras, em que a segunda, Marajó, não indica a continuação da história de Alfredo, retomada apenas em Três Casas e um Rio, seu terceiro romance, e levada adiante até o último, Ribanceira. Deste modo, Marajó, iniciado antes da prisão, embora ambientado na Amazônia, não possui Alfredo como protagonista, nem como personagem. Há muitas hipóteses para explicar esse aparente "desvio" no alinhamento narratológico do ciclo e, assim sendo, ensaiamos pensar em mais uma, dentro da proposta de reflexão desse texto. Teria a prisão, de fato, e, sobretudo, a leitura de Dom Quixote no cárcere, impulsionado a ideia da criação do projeto estético do escritor?

O ensaio aqui caminha para a possibilidade de haver uma relação emulativa entre o lido e o escrito. Desse modo, o projeto literário de Dalcídio Jurandir se dedica a descrever um ciclo de acontecimentos que desvelam sob o olhar do protagonista Alfredo os problemas da sociedade amazônica, fazendo-nos compreender, mediante suas estratégias narratológicas, que se nutrem de um sentimento de alteridade para com o sofrimento alheio, uma vivência profunda da tragédia do homem moderno envolvido entre expectativas e desilusões. Nesse aspecto, portanto, percebem-se as nuances quixotescas desse ciclo, no sentido pelo qual os ideais de progresso e mudança são desconstruídos de forma trágica, abjeta, mas também cômica em algumas vezes, na medida em que se dá o despertar de Alfredo em contato com suas desventuras e as agonias alheias. 
Ademais, podemos considerar que o próprio posicionamento político e literário do escritor é motivado por ideais quixotescos, pois a catástrofe amazônica de sua obra, embora pareça cheia de pessimismo, é movida por um desejo de denúncia e de persistente vontade de encontrar a mudança, mesmo que ela não pareça viável. É possível que ao fazer opção por uma ficção densamente matizada por essas nuances Dalcídio Jurandir tenha trazido a sua escrita as repercussões da marca do Quixote: o profundo humanismo, o enfrentamento dos «conceitos tradicionais de 'limpeza de sangue' e diferença entre linhagens" e a contraposição às contradições de sua época (AGUINAGA apud WITEZE JR, 2011, p. 214).

É importante esclarecer que tais especulações fazem parte de uma fase introdutória de reflexão que reside num primeiro momento em se considerar a relação entre o fato de Dalcídio Jurandir ter lido Dom Quixote no cárcere, num contexto de repressão, e as reverberações filosófico-literárias que se inserem na teia da invenção de um tipo de pensamento, gerado em um tempo e espaço específicos.

Ao observarmos que a fortuna crítica sobre a relação entre literatura e cárcere contempla em sua maioria, produções focadas na escrita testemunhal sobre a experiência da prisão e da exceção, ou seja, em memórias dessa experiência, constatamos que a originalidade em se pensar o caso da prisão política de Dalcídio Jurandir está em abordar um aspecto ainda não explorado nesse sentido, a saber, o leitor e o escritor na mesma pessoa em uma condição de exceção. Compreendemos que esse processo se torna minucioso, pois, num contexto carcerário, em que os livros eram de certa forma vetados ou restringidos, perguntamos-nos quais os critérios e necessidades desse escritor, ao escolher e solicitar para a esposa, por carta, alguns livros específicos, em detrimento de outros.

Pensar a relação entre a experiência carcerária e a atividade intelectual faz parte dos estudos de Roberto Vecchi (2015) ao propor o conceito de claustrosofia. Para o filósofo, o cárcere pode ser o produtor de um saber peculiar, um modulador do pensamento em condições especiais:

A coação das dimensões do tempo e do espaço - um tempo enorme, corpulento como o define Gramsci, mas não infinito, e um espaço exíguo, augusto, cerrado influenciaria o sujeito interpretativo, assim como afetaria as representações ou a elaboração que decorrem do aprisionamento, como se a subtração se tornasse, pelo contrário, a potência de uma condição forçadamente isolada, excepcional (VECCHI, 2015, p. 208).

Ressalta-se que a reflexão de Vecchi sobre esse aspecto é inspirada na produção literária de importantes personalidades como Antonio Gramsci, dentre outros, a partir de seus relatos acerca de 
sua experiência de prisão, em Quaderni Del cárcere (1948), escritos entre 1926 e 1937, quando esteve preso na Itália. Nesse caso, o estudo da claustrosofia volta-se, em princípio, para a ótica do testemunho do cárcere. Vecchi discute sobre o paradoxo do confinamento carcerário: "De fato, será que a prisão preserva e alimenta uma relação especial com o pensamento? A experiência do cárcere como comunica com uma especulação crítica e, sobretudo, é possível individuar uma espécie de pensamento do cárcere?” (VECCHI, 2015, pág. 208).

Desse modo, se a prisão, na perspectiva de Vecchi pode ser capaz de modular o posicionamento do intelectual, detido sob repressão política, a condição de exceção a qual esse indivíduo pensante é inserido transmuta-se em potência criativa. Portanto, é possível considerar que a leitura enquanto uma atividade intelectual realizada na experiência do cárcere exerce importante influência na construção do pensamento, ou seja, o leitor na prisão elabora também suas reflexões em torno do interior e do exterior do lugar de repressão. Logo, a cela, ao invés de se tornar um espaço de limitações, ressignifica o universo desse intelectual nela inerente. Deste modo, os livros lidos ganham uma dimensão diferenciada, tornando-se também um material de pesquisa para a compreendermos as nuances de construção das obras desses autores.

No Brasil, temos atualmente um exemplo bastante curioso sobre a relação entre leitura na cela e produção literária. Trata-se da história do parlamentar João Paulo Cunha, preso durante as investigações sobre o mensalão:

No dia em que se apresentou na Papuda para cumprir pena, o então deputado federal João Paulo Cunha - o primeiro político condenado no mensalão - carregava um saco com roupas, lençol, toalha e escova de dente. A completar a leve bagagem do cárcere, quatro livros. A seleção de títulos era sugestiva: Ficções, do argentino Jorge Luis Borges; Diário da Queda, do gaúcho Michel Laub; Operação Banqueiro, do jornalista Rubens Valente; e Vermelho Amargo, do mineiro Bartolomeu Campos de Queirós. Pelos seus cálculos, foram cerca de sessenta volumes durante um ano e vinte dias de prisão em regime semiaberto. “Depois, pensei: por que só ler?” Tempo não lhe faltava. Ele, então, começou a anotar ideias num bloquinho. Como se tomado por Antonio Gramsci, se animou a transformar suas reflexões em resenhas e dividi-las com o público. O resultado são os 21 textos críticos reunidos no volume Janelas do Cárcere: Para quando Faltar Horizonte, ainda sem previsão de lançamento. No livro, Cunha examina obras de autores como Leonardo Padura, Chico Buarque e John Boyne. ${ }^{3}$.

João Paulo Cunha, portanto, embora as circunstâncias de sua prisão não sejam louváveis do ponto de vista ideológico comparado a Dalcídio Jurandir, não deixa de ser um exemplo sobre a relação entre leitura no cárcere e o impulso criativo. Resta-nos verificar tais resenhas a fim de identificar as

${ }^{3}$ Reportagem disponível em: http://piaui.folha.uol.com.br/materia/resenhas-do-carcere/ 
nuances e influências desse espaço em seus textos e a claustrosofia existente neles. De que modo podem contribuir para uma visão quem sabe peculiar das obras dos autores lidos?

O trabalho em questão, portanto, coloca perante o paradoxo de Vecchi um elemento específico para se refletir sobre essa relação com o pensamento que é o ato de leitura do escritor no espaço carcerário. Nesse momento, no entanto, a intenção ainda não foi realizar a análise literária da obra de Dalcídio Jurandir a partir dessas influências, mas abordar alguma relação existente entre o autor e a obra lida, no caso Dom Quixote de La Mancha.

Para finalizar, salientamos que em 1947 Dalcídio Jurandir escreve um texto em homenagem a comemoração do centenário de Cervantes:

Por que de algum modo nos sentimos envergonhados diante do quarto centenário de Cervantes que se comemorou em meio a insânia das provocações de guerra e dentro ainda do regime de Franco na Espanha? Essa vergonha é um sentimento quixotesco, autêntico e vivo como a paixão do Cavaleiro da Triste Figura pela verdade. Deixamos de rir de Quixote, de interpretar-lhe os símbolos e as intenções, de acreditar que é vão o seu heroísmo e que é loucura o que ele faz nas suas aventuras. Desde as primeiras páginas do livro sentimos logo a autenticidade da vida que se desenrola, o Cavaleiro não se volta para os livros de cavalaria, nem encontra miragens pela frente, suas aventuras são verdadeiras, sua cólera, seu ódio ao mal, sua dignidade e seu sacrifício pelos oprimidos estão conosco e se incorporam à história dos atuais guerrilheiros da Espanha. [...] O livro que é uma sátira contra a idade média, que encarna o fim da ideologia feudal, transforma-se em manifesto político do nosso drama, guia de ação e heroísmo em toda a parte, onde é necessário derrotar os monstros fascistas, os inimigos da liberdade, a opressão e a mentira. Vemos que Cervantes está, em verdade, encarcerado na Espanha. Todas as comemorações que Franco tenta fazer no centenário são pura farsa, pura ofensa e puro insulto. São os velhos inimigos de Cervantes, os que o infamaram há trezentos anos, os seus caluniadores e verdugos que dominam a sua Espanha. Para Quixote são monstros, contra os quais saíra em aventura pelo mundo, qua assaltaram a sua pátria, que a governam em barataria, sangram o povo, espalhando a injustiça e o terror. Ninguém duvida que a destruição de Quixote é a destruição da liberdade.

Essa citação reforça a associação emulativa de que falamos anteriormente. Nesse contexto, é interessante notar que a reflexão crítica de Dalcídio Jurandir perpassa pelas suas impressões de leitor, sobretudo quando diz "Deixamos de rir de Quixote, de interpretar-lhe os símbolos e as intenções, de acreditar que é vão o seu heroísmo e que é loucura o que ele faz nas suas aventuras”. De certa forma, tal ponto de vista exposto no texto, coincide com a ética do próprio autor, na formação de seus ideais políticos e estéticos que residem na vontade da denúncia, das injustiças e na busca pela liberdade. A 
vergonha, a qual ele denomina de sentimento quixotesco, muito ligado à ofensa, é possível de estar presente e também fazer entender (e estender) no universo de criação de seus personagens.

Dalcídio Jurandir, ao retratar uma Amazônia em permanente estado de exceção, traz para sua obra o sentimento de abandono, de encurralamento, de sufocamento. Deste modo, nos indagamos juntamente com Vecchi sobre a existência de uma claustrosofia independente das narrativas do cárcere: “Ou seja, enquanto nómos do moderno, as claustrosofias poderão ou não tornar-se pensamento sobre a modernidade e as barbáries modernas?” (VECCHI, 2015, p. 217). Nesse sentido, entender a leitura em cárcere como uma forma de claustrosofia contribui para dimensionar o conceito de Vecchi em novos horizontes de pesquisa.

\section{REFERÊNCIAS}

BOSI, Alfredo. Literatura e Resistência. São Paulo: Companhia das Letras, 2002.

CORNELSEN, Elcio. O "escritor operativo", o engajamento e a resistência. In: SARMENTOPANTOJA, Augusto; SARMENTO-PANTOJA, Tânia, UMBACH, Rosani (Org). Estudos de Literatura de Resistência. São Paulo: Pontes, 2014

MORES, Viviane Dantas. A vida nua em Dalcídio Jurandir. Metamorfoses do estado de exceção. Tese. Programa de Pós-Graduação em Letras. Universidade Federal do Pará: Belém, 2017.

PEREZ, Renard. Escritores brasileiros contemporâneos. Rio de Janeiro: 1964.

VECCHI, Roberto. As potências da claustrosofia: limiares políticos do pensamento e da Literatura do Cárcere. In: Literatura e Memória política. Angola. Brasil. Moçambique. Portugal. ABDALA JÚNIOR, Benjamin; VECHIA ROCHA E SILVA, Rejane. São Paulo: Ateliê Editorial, 2015.

WITEZE JÚNIOR, Geraldo. Os muitos caminhos do Quixote: pluralidade de vozes e interpretação. Memento, V. 2, n. 2, ago.-dez. $2011 \quad$. $\quad$ Disponível em file://C:/Users/eletro\%20magazan/Downloads/DialnetOsMuitosCaminhosDoQuixote-3873758.pdf

Recebido em 30 de setembro de 2018

Aceito em 28 de dezembro de 2018 